\title{
INTERDISCIPLINARIDADE: A PERCEPÇÃO DOS TRABALHADORES SOCIAIS DOS CENTROS DE REFERÊNCIA DE ASSISTÊNCIA SOCIAL (CRAS)
}

\author{
INTERDISCIPLINELITY: THE PERCEPTION OF THE \\ SOCIAL WOKS OF SOCIAL ASSSISTENCE REFERENCE \\ CENTIES (CRAS)
}

\author{
Juliana Alves Barbosa* \\ Elisa Maria Andrade Brisola ${ }^{* *}$
}

\begin{abstract}
RESUMO
Este artigo apresenta um recorte da dissertação de Mestrado, cujo objetivo busca refletir a percepção dos profissionais dos Centros de Referência de Assistência Social (CRAS) sobre o trabalho interdisciplinar. A abordagem foi qualitativa, para coleta de dados utilizou-se metodologia da História Oral e a técnica de entrevistas a partir de eixos norteadores. A pesquisa foi aplicada com três assistentes sociais e três psicólogos (as), para análise utilizou-se a triangulação. As análises mostram a importância da temática pesquisada, pois embora não consiga conceituar o que é interdisciplinaridade, maior parte dos profissionais revela que seu trabalho é interdisciplinar, o que favorece uma intervenção na totalidade, ultrapassando o mundo das espacializações e da fragmentação, buscando garantir deste modo a política de Assistência social como direito.
\end{abstract}

Palavras Chaves: Interdisciplinaridade. Trabalhador Social. Política de Assistência Social.

\begin{abstract}
This paper shows a pice of Máster dissertation, whose aim searches to reflect the perception of the works of CRAS about the interdiscipline work. The approach was qualitative, to collect data was used Oral History methodology and the interview technic with three social assistants and three psychologists to analyis was used the triangle. The analyses show the importance of the theme searchad, even though the professional can't concept what interdisciplinelity is, the most of the professionals reveals that their work is interdisciplinal, what favors an intervention in the totality, getting ahead of the world of the specializations and of the fragmentation, searching to guarantee this way the politics of Social Assistence as right.
\end{abstract}

Keywords: Interdisciplinelity. Social worker. Social Assistence Politics.

\footnotetext{
“Mestranda em Desenvolvimento Humano: Formação, Políticas e Práticas Sociais- PRPPG- Universidade de Taubaté, juliana-alvesbarbosa@hotmail.com ** Docente do Programa de Mestrado em Desenvolvimento Humano: Formação Política e Práticas Sociais- PRPPG- Universidade de Taubaté, elisabrisola@ uol.com.br
} 


\section{Introdução}

Este estudo reflete sobre o trabalho social interdisciplinar realizado no âmbito da política de assistência social pelos trabalhadores sociais (assistentes sociais e psicólogos) em Pindamonhangaba, município de grande porte, da região metropolitana do Vale do Paraíba paulista.

A escolha do tema deveu-se ao fato de que na sociedade brasileira contemporânea a questão social ${ }^{1}$ é agravada pelas necessidades da população, que aumentam em conseqüência do desemprego, da violência e da pobreza entre outros resultados da desigualdade social e da crise de acumulação do capital $^{2}$.

No Brasil, logo depois de um longo processo de luta política ${ }^{3}$ pela implementação da assistência social como política pública, no ano de 2004, aprova-se a Política Nacional de Assistência Social (PNAS) e em 2005 a Norma Operacional Básica do Sistema Único de Assistência Social (NOB-s). Esses fatos alteraram os rumos da assistência social no país, impondo a necessidade de mudanças tanto na gestão da política como nas práticas profissionais dos trabalhadores sociais. Inicia-se a construção "de um novo tempo", ou seja, a assistência social,

\footnotetext{
A questão social é entendida aqui como "indissociável do processo de acumulação e dos efeitos que produz sobre o conjunto das classes trabalhadoras, o que se encontra na base da exigência de políticas sociais públicas. Ela é tributária das formas assumidas pelo trabalho e pelo Estado na sociedade burguesa e não um fenômeno recente, típico do trânsito do padrão de acumulação no esgotamento dos 30 anos gloriosos da expansão capitalista" (IAMAMOTO, 2004, p. 11); período após Segunda Guerra Mundial, quando se adentrou na fase madura do capitalismo, "esta foi marcada em seus 30 anos por uma forte expansão, com taxas de lucros altas e ganhos de produtividade para empresas, políticas sociais para trabalhadores [...] esse período dos anos 1960 (BEHRING; BOSCHETTI, 2011, p.82). Dito de outra maneira, a chamada questão social "pode ser analisada como sendo o conflito social que expressa a organização da sociedade de classes, onde o trabalho assalariado é subordinado ao capital, enfrentando as crises cíclicas da economia em que ocorrem desemprego e redução de salários, afetando de forma negativa as condições de vida dos trabalhadores. A insegurança e o risco são inerentes à questão social. "O conflito social se traduz em conflito político, expresso na atuação do Estado em cada momento histórico" (COSTA, 2007, p.35).

${ }^{2}$ A crise de acumulação do capital desde os anos de 1970 do século XX é explicada por muitos autores, entre eles, Ernest Mandel (1990) segundo o qual as crises do capital são inerentes à sua própria lógica e possuem um caráter cíclico. As crises do capital "expressam um desequilíbrio entre a produção e o consumo, comprometendo a realização do capital, ou seja, sua transformação da mais-valia em lucro. [...] As expressões mais emblemáticas das crises são as reduções das operações comerciais, acúmulo de mercadorias estocadas, falências, queda de preços e salários, crescimento desmesurado do desemprego", entre outras (MOTA, 2009, p. 53).

${ }^{3}$ Desde 1993 com a aprovação da Lei Orgânica da Assistência Social (LOAS).
}

“como política social pública, começa seu percurso para o campo dos direitos, da universalização dos acessos e da responsabilidade estatal" (YAZBEK, 2008, p.3).

No que tange aos trabalhadores sociais no SUAS, estes ganham importância, pois deles depende a implementação do sistema na perspectiva do direito, uma vez que atuam diretamente com a população usuária dos serviços socioassistenciais. Evidentemente, não se excluem as responsabilidades dos gestores (em cada ente federativo) visto que o sistema é público e estatal: logo sua implementação deve contar com "vontade política", bem como com recursos financeiros e orçamentários para sua execução.

Assim, entender como o trabalho interdisciplinar é compreendido/realizado pelos trabalhadores sociais, em especial da perspectiva teórico metodológica, no âmbito do SUAS nos Centros de Referência de Assistência Social (CRAS) é fundamental, na medida em que a PNAS objetiva "prover serviços, programas, projetos e benefícios de proteção social básica e, ou, especial para as famílias, indivíduos e grupos que delas necessitarem", de forma a assegurar que as ações tenham centralidade na família e que garantam a convivência familiar e comunitária (PNAS, 2004, p.33).

Nesse sentido, busca-se refletir sobre o trabalho interdisciplinar a partir da percepção dos trabalhadores sociais (em especial os assistentes sociais e psicólogos), pois nas "sociedades contemporâneas, a crise dos paradigmas na construção do saber apresenta os dilemas, os conflitos, as crises, as dúvidas, as incertezas que ocorrem no conjunto das relações sociais" (CAVALCANTE; MORTARA, 2004, p.94).

Portanto, quando se pensa na ação interventiva dos assistentes sociais e psicólogos nos CRAS, percebe-se que essa temática é vital, pois, "na violação de direitos, estamos nós na crista da onda, intervindo a partir de modelos estabelecidos por nossas verdades - estas datadas e construídas sócio-historicamente" (FRAGA, 2011, p. 184-185).

\footnotetext{
${ }^{4}$ Embora a PNAS não se dirija diretamente ao trabalho interdisciplinar (conceitos e diretrizes), é necessário ressaltar que o documento Caderno de Orientações sobre o Programa de Atenção Integral à Família (2012, p. 88) traz em sua redação: "a adoção de quaisquer abordagens metodológicas exige tratamento interdisciplinar [...] e constante repensar dos profissionais sobre sua prática".
} 
É, preciso esclarecer que, no pensamento marxiano, "as ideias dominantes de uma época representam sempre as ideias da classe dominante economicamente daquela sociedade" (GADOTTI, 1989, p. 47), ou seja, "é na prática humana coletiva, na experiência das sociedades, que o homem tem de demonstrar, e construir, a verdade" (GADOTTI, 1989, p. 49).

Evidencia-se que a perspectiva adotada parte de um referencial crítico e, nesse sentido, reconhece as contradições que atravessam o processo de construção dessas práticas, visto que os trabalhadores sociais são trabalhadores assalariados que atuam também no contraditório Estado burguês (IAMAMOTO, 2009).

Desse modo, a intervenção desses profissionais pensada interdisciplinarmente conseguiria romper com o ordenamento social do capital, bem como com o mundo de especialzações que fragmenta o sujeito, pois parte-se do pressuposto de que a interdisciplinaridade permite que um profissional conheça qual é a concepção de mundo, de homem e de sociedade que outro profissional tem para poder identificar possíveis pontos de diálogos e de intercessão no trabalho em conjunto, ou seja,

[...] criar espaços democráticos e plurais permanentes no interior das equipes para que possam planejar em conjunto as suas ações, pois somente assim é possível discutir com honestidade e segurança os limites e potencialidades da intervenção de cada profissional (ORTIZ, 2011, p. 199).

\section{Esclarecendo conceitos:}

\section{A política de assistência social e o SUAS}

Diante da crescente demanda e dos seus diversos perfis, apresentados aos profissionais da política de assistência social, nota-se que é fundamental criar novas articulações e estratégias de atuação e intervenção.

Nessa perspectiva, a Política Nacional de Assistência Social (PNAS) e o Sistema Único de Assistência Social (SUAS) desde 2005 estabelecem uma política que prevê a diversidade e as diferenças sociais em todo o território nacional, bem como consegue estabelecer o parâmetro de direito e não de benemerência, buscando assim romper com o caráter filantrópico que marcou a história da assistência social.

Para tanto, o SUAS estabelece dois níveis de proteção social: básica de caráter preventivo e especial - quando ocorre violação de direitos ${ }^{5}$ bem como organiza e define elementos essenciais à execução da política de assistência social, sendo eles: matricialidade sócio familiar; descentralização político - administrativa e territorialização; novas bases para relação entre Estado e sociedade civil; financiamento; controle social; política de recursos humanos; informação, monitoramento e avaliação.

Desse modo, o SUAS modelo de gestão descentralizado e participativo, constitui-se na regulação e na organização de serviços socioassistenciais, tendo como foco as famílias e o território como base de organização (BRASIL, 2004).

Priorizando a proteção social básica, sem dar menos importância à especial, é válido enfatizar que a proteção social básica se realiza a partir de um equipamento público "capaz" de garantir a atenção integral às famílias em determinado território o Centro de Referência de Assistência Social (CRAS), também conhecido como Casa da Família.

Assim, o Centro de Referência de Assistência Social é: ${ }^{6}$

- a unidade estatal responsável pela oferta de serviços continuados de proteção social básica de assistência social às famílias, grupos e indivíduos em situação de vulnerabilidade social;

- a unidade efetivadora da referência e contra-referência do usuário na rede socioassistencial do Sistema Único de Assistência Social (SUAS) e unidade de referência para os serviços das demais políticas públicas;

- a "porta de entrada" dos usuários à rede de proteção social básica do SUAS;

- a unidade que organiza a vigilância social em sua área de abrangência;

- uma unidade pública que concretiza o direito socioassistencial quanto à garantia de acessos a serviços de proteção social básica com matricialidade sócio familiar e ênfase no território de referência;

\footnotetext{
${ }^{5}$ Para maiores informações vide Norma Operacional Básica do SUAS.

6 Manual de Orientações Técnicas para o Centro de Referência de Assistência Social, junho/2006, p. 13.
} 
- um equipamento onde são necessariamente ofertados os serviços e ações do Programa de Atenção Integral à Família (PAIF) e onde podem ser prestados outros serviços, programas, projetos e benefícios de proteção social básica relativos às seguranças de rendimento, autonomia, acolhida, convívio ou vivência familiar e comunitária e de sobrevivência a riscos circunstanciais.

Destarte, os programas, projetos e serviços desenvolvidos no CRAS com as famílias e indivíduos em seu contexto comunitário, visam à orientação e ao convívio sociofamiliar e comunitário, evitando a focalização e o trabalho por segmentos. Tais ações são desenvolvidas com o membro da família, com o grupo familiar ou com grupos de famílias (BRASIL, 2004).

Portanto, conforme a Resolução $n^{\circ} 109$, de 11 de novembro de 2009, que aborda da Tipificação Nacional de Serviços Socioassistenciais, afirma-se:

[...] proteção social básica: trabalho social com as famílias de caráter continuado, com a finalidade de fortalecer a função protetiva das famílias, prevenir a ruptura de seus vínculos, promover seu acesso e usufruto de direitos e contribuir na melhoria da qualidade de vida (BRASIL, 2009).

Nessa ótica, ao se introduzir a questão dos serviços socioassistenciais nas perspectivas de continuidade, prevenção, proteção e qualidade de vida, torna-se imprescindível falar do trabalho interdisciplinar, pois:

O trabalho dos assistentes sociais e psicólogos na política de assistência social requer interface com as políticas da saúde, previdência, educação, trabalho, lazer, meio ambiente, comunicação social, segurança, habitação, na perspectiva de mediar o acesso dos(as) cidadãos(ãs) aos direitos sociais. As abordagens das duas profissões podem somar-se com o intuito de assegurar uma intervenção interdisciplinar capaz de responder a demandas individuais e coletivas, com vistas a defender a construção de uma sociedade livre de todas as formas de violência (...). Ao integrar a equipe dos(das) trabalhadores(as) no âmbito da política de Assistência Social, esses profissionais podem contribuir para criar ações coletivas de enfrentamento a essas situações, com vistas a reafirmar um projeto ético e sociopolítico de uma nova sociedade que assegure a divisão equitativa da riqueza socialmente produzida. Dessa forma, o trabalho interdisciplinar deve ser orientado pela perspectiva de totalidade, com vistas a situar o indivíduo nas relações sociais que têm papel determinante nas suas condições de vida, de modo a não responsabilizar o indivíduo pela sua condição socioeconômica (CFESS, 2007).

Desse modo, o trabalho interdisciplinar torna-se uma possibilidade de intervenção ao assistente social e ao psicólogo, de acordo com seus parâmetros de atuação citados abaixo.

$\mathrm{O}$ assistente social deve realizar:

- a leitura crítica da realidade e capacidade de identificação das condições materiais de vida;

- identificação das respostas existentes no âmbito do Estado e da sociedade civil, reconhecimento e fortalecimento dos espaços e formas de luta e organização dos(as) trabalhadores(as) em defesa de seus direitos;

- formulação de construção coletiva, em conjunto com os(as) trabalhadores(as), de estratégias políticas e técnicas para modificação da realidade e formulação de formas de pressão sobre o Estado, com vistas a garantir os recursos financeiros, materiais, técnicos e humanos necessários à garantia e à ampliação de direitos (CFESS, 2007, p. 17).

O psicólogo deve:

- realizar diagnóstico e avaliação de processos psicológicos de indivíduos, de grupos e de organizações;

- realizar diagnóstico psicossocial que viabiliza a construção de projetos de intervenção;

- coordenar e manejar processos grupais, considerando as diferenças individuais e socioculturais dos seus membros (CFESS, 2007, p. 35)

Mais:

Uma das possibilidades do trabalho realizado na comunidade com as famílias, grupos e indivíduos, pelos psicólogos, é a exploração e a compreensão dos significados presentes nas ações do sujeito, bem como dos grupos de sujeitos, buscando-se-lhes apreender o sentido que leva a determinadas direções de relacionamentos, conflitos e decisões com foco na construção de novas respostas (CFESS, 2007, p. 36). 
Logo, este artigo pretende proporcionar momentos de reflexão e autocrítica aos profissionais, antes mesmo de ser um trabalho indagador, criador e/ou esclarecedor.

\section{A interdisciplinaridade e Multidisciplinaridade}

Embora a prática e a intervenção dos profissionais da política de assistência social ensejem grandes debates há tempos, elas têm sido pensadas pelos profissionais de forma diferenciada, pois ponderar suas potencialidades na atual política é essencial, uma vez que a PNAS propõe para os CRAS uma equipe multidisciplinar que desenvolva ações interdisciplinares.

Isso significa que esse novo contexto exige do profissional um posicionamento interdisciplinar, que respeite a especificidade de cada profissional, mas que não expresse ações fragmentadas.

Conforme Lenoir (2005, s.p) "a palavra interdisciplinaridade atravessou fronteiras e, atualmente, dá a volta ao planeta [...] a noção de interdisciplinaridade, como tantas outras, aliás, é polissêmica [...]".

A consulta de diversos autores (FAZENDA, 2003, 2002; LENOIR, 2005; MINAYO, 2010; FURLANETTO, 2011; ORTIZ, 2011; POMBO, s.d) mostra que a noção de interdisciplinaridade é recente. Embora se constatem infinitos avanços na ciência, a fragmentação do saber, o aumento do número de disciplinas e o questionamento do papel social da ciência no mundo contemporâneo, principalmente após as atrocidades como Hiroxima e Nagasaki levaram a novos debates a respeito da interdisciplinaridade (FURLANETTO, 2011).

É importante ressaltar que foi na década de 1960 e no início da década de 1970 que a crítica às teorias totalizantes e à ciência compartimentada, com base na filosofia da consciência que separa o sujeito do objeto, se fortaleceram entre os intelectuais estudiosos (MINAYO, 2010).

Assim, o debate sobre interdisciplinaridade de acordo com Lenoir (2005, p. 49) "ultrapassou questões que se preocupavam somente com a integração das disciplinas, mas também com as consequências e os produtos dessa interação". Para o autor o debate se articulou em três eixos:

- interrogação epistemológica - Diz respeito aos países franceses: preocupava-se com a exploração das fronteiras das disciplinas e dos sentidos e da consequência desse tipo de conhecimento, com o intuito de ampliar as possibilidades de compreensão da interdisciplinaridade;

- questionamento social - Diz respeito à pesquisa realizada na América do Norte: a questão central não é o saber, mas a funcionalidade;

- ligação com as atividades cotidianas - Refere-se às necessidades das sociedades industriais e ao fenômeno da globalização.

Lenoir também apresenta mesmo que minimamente, um quarto eixo, que se se caracterizaria com a interdisciplinaridade no Brasil, a qual é introspectiva e que se preocupa em enfatizar o papel do sujeito na produção de conhecimento.

Nessa perspectiva, seguem-se alguns conceitos trazidos pelos autores sobre interdisciplinaridade:

"Ela está destinada a mover-se nas fronteiras de territórios estanques e separados, procurando descobrir brechas e permeabilidades no espaço do entre que permitam estabelecer novas relações" (FURLANETTO, 2011, p. 48).

"[...] a interdisciplinaridade constitui uma articulação de várias disciplinas em que o foco é o objeto, o problema ou o tema complexo, para o qual não basta a resposta de uma área só" (MINAYO, 2010, p. 436)

Minayo (2010, p. 439) escreve:

Vale a pena lembrar que, na abordagem interdisciplinar, o grupo de vários especialistas deve rever em conjunto a teoria com que quer trabalhar e colocar em debate os conceitos de cada área a serem problematizados e articulados: suas diferenças e possibilidades de colaboração.

E acrescenta que várias são as nuances para o tratamento de um objeto de forma interdisciplinar:

- sempre uma disciplina terá prioridade sobre outras por ser a que tem mais tradição, história e acúmulo de conhecimento sobre o assunto;

- é evidente que essa preeminência não pode se constituir na anulação da contribuição das outras disciplinas;

- o trabalho interdisciplinar nunca deve propor a contribuição que vem de uma disciplina;

- na articulação entre as disciplinas, é preciso que cada uma das áreas apresente conceitos e teorias capazes de ampliar e complexificar a compreensão do objeto. 
Pode-se afirmar que tais premissas fundamentaram a análise dessa, em função do conteúdo teórico-metodológico apresentado. No entanto são os trabalhos de Fazenda (2002; 2003); Cavalcante e Mortara (2004); Eidelwein (2007); Ortiz (2011) e Pombo (s.d) que subsidiam as análises na sua totalidade, já que esses autores trabalham a concepção do diálogo e refletem que o indivíduo está inserido em uma realidade social problemática sob numerosos aspectos, ou seja, para eles a interdisciplinaridade traz também "um projeto político no plano educativo, o de propor outras maneiras de conceituar a sociedade, outras ações e abordagens e assim, outras visões de relações sociais mais respeitosas da dimensão humana" (LENOIR, 2005, s.p). Além disso, a relação integradora entre teoria e prática proposta pela interdisciplinaridade trazida por esses autores "implica na construção de ações críticas transformadoras no interior da sociedade capitalista" (PIRES, 1998, p. 177), e eles, discutem a interdisciplinaridade na perspectiva do contexto da temática debatida na pesquisa.

Muito se ouve falar de multidisciplinaridade e de interdisciplinaridade, mas se faz necessário buscar uma compreensão mais profunda desses conceitos, visto que é fundamental identificar as diferenças entre eles. Afinal, "a ideia de integração e de totalidade, que aparentemente perpassa estes conceitos, tem referenciais teórico-filosóficos diferentes, antagônicos, mas complementares" (ALVES; REINERT, 2007, p. 691).

Para esses autores, a multidisciplinaridade "foi considerada importante para acabar com um ensino extremamente especializado, concentrado em uma única disciplina [...]", e "[...] a multidisciplinaridade ocorre quando a solução de um problema torna necessário obter informação de duas ou mais ciências ou setores do conhecimento sem que as disciplinas envolvidas no processo sejam elas mesmas modificadas ou enriquecidas" (ALVES; REINERT, 2007, p. 692).

Ademais, para outros autores a "principal característica das relações em que ocorre esse tipo de abordagem (multidisciplinar) é a justaposição de ideias" (BICALHO; OLIVEIRA, 2011, p. 7). Para Nicolescu et al. (2000, apud BICALHO; OLIVEIRA, 2011, p. 7) “ a multidisciplinaridade corresponde à busca da integração de conhecimentos por meio do estudo de um objeto de uma mesma e única disciplina ou por várias delas ao mesmo tempo."

Para Delattre (2006, apud BICALHO; OLIVEIRA, 2011, p. 8), a multidisciplinaridade pode ser entendida como:

Uma simples associação de disciplinas que concorrem para uma realização comum, mas sem que cada disciplina tenha que modificar significativamente a sua própria visão das coisas e dos próprios métodos [...]. Toda realização teórica que compõe em prática saberes diversos corresponde de fato a um empreendimento pluridisciplinar.

Com base nesses pressupostos afirma-se que a diferença entre interdisciplinaridade e multidisciplinaridade estaria na busca da integração da metodologia e dos conteúdos, ou seja, a multidisciplinaridade não abriria espaço para tais integrações, somente para compartilhar saberes.

Já a interdisciplinaridade, conforme Domingues (2005, apud BICALHO; OLIVEIRA, 2011, p. 11) apresenta três características básicas:

- aproximação de campos disciplinares diferentes para solução de problemas específicos;

- compartilhamento de metodologia;

- geração de novas disciplinas após muita cooperação e fusão entre os campos.

Porém, vale ressaltar algumas experiências chamadas multidisciplinares que também são elencadas pelo autor (DOMINGUES, 2005, p. 22 apud BICALHO; OLIVEIRA, 2011, p. 8):

- aproximação de diferentes disciplinas para a solução de problemas específicos;

- diversidades de metodologias: cada disciplina fica com a sua metodologia;

- os campos disciplinares, embora cooperem, guardam suas fronteiras e ficam imunes ao contato.

Contudo, o amadurecimento sobre tais conceitos é pertinente, uma vez que proporcionou melhor entendimento do seu significado e uma melhor adequação à metodologia adotada no desenvolvimento da pesquisa.

Todavia, é preciso coerência para não ser pragmático, principalmente quando se menciona que o trabalho desenvolvido nos CRAS é interdisciplinar, ao mesmo tempo que é realizado e/ou executado por uma equipe multidisciplinar. 


\section{Metodologia}

A priori, ao partir da concepção de que a realidade vivenciada pelos sujeitos e pela pesquisadora está em constante construção, e de que não é possível compreendê-la em sua imediaticidade ${ }^{7}$, mas sim inserida numa ótica de totalidade e historicamente determinada, a pesquisa pretendeu refletir acerca de questionamentos propostos a partir de uma linha teórico-metodológica crítica, embasada na perspectiva histórica e dialética da realidade social.

A respeito dos procedimentos técnicos, utilizou-se como metodologia a história oral, e como técnica para coleta de dados a entrevista, a partir de um roteiro, que se constituiu em eixos norteadores da análise, esta se deu pela metodologia/técnica de triangulação.

A pesquisa foi realizada com seis sujeitos, sendo três psicólogos e três assistentes sociais, num universo de três assistentes sociais e seis psicólogos nos CRAS. Tal demanda partiu do princípio de que a amostragem do universo da pesquisa teve como principal preocupação "[...] abranger a totalidade do problema investigado em suas múltiplas dimensões" (MINAYO, 1994, p.43), uma vez que, a escolha dos sujeitos da pesquisa constitui uma etapa importante, em que se obtém maior proximidade dos fatos e informações mais concisas a cerca da realidade. A escolha do município deu-se por três fatores: primeiro, baseou-se na divisão por porte ${ }^{8}$ estabelecida pela PNAS, a qual se orienta pelo Instituto Brasileiro de Geografia e Estatística (IBGE); segundo, o município apresenta cinco CRAS em territorialidades bem distintas, o que proporcionou maior representatividade nos resultados obtidos terceiro, a acessibilidade, pois a pesquisadora reside e trabalha no município.

Ressalta-se que projeto foi submetido ao Comitê de Ética da Universidade de Taubaté conforme

\footnotetext{
7 "A aproximação dialética no conhecimento da singularidade não pode ocorrer separadamente das suas múltiplas relações com a particularidade e com a universalidade. Estas já estão contidas no dado imediatamente sensível de cada singular, e a realidade e a essência deste só pode ser compreendida quando estas mediações (as relativas particularidades e universalidades) ocultas na imediaticidade são postas à luz" (LUKÁCS, 1978, p. 106, apud PONTES, 1999, p. 17)

${ }^{8}$ Considera-se o município de Pindamonhangaba de grande porte, já que pela classificação do IBGE (2007) os município que possuem até 20.000 habitantes são considerados pequeno porte 1; os que possuem de 20.001 até 50.000 são considerados pequeno porte 2; os que possuem 50.001 a 100.00 são de médio porte e os que possuem de 100.001 a 900.000 habitantes são considerados grande porte.
}

preconiza a resolução 196/96 do Conselho Nacional de Saúde. Após aprovação CEP 508, encaminhou-se um ofício para o Departamento de Assistência Social solicitando autorização para a realização das entrevistas.

Depois da autorização da diretora do departamento realizou-se uma reunião com os profissionais do referido setor, na qual se apresentou a pesquisa e seus objetivos; a partir daí os profissionais interessados em participar se prontificaram voluntariamente e foram orientados quanto ao Termo de Consentimento Livre e Esclarecido.

As entrevistas com os trabalhadores sociais foram previamente agendadas e executadas (dezembro de 2011) separadamente. Antes do início das mesmas, cada profissional respondeu a um questionário de identificação e assinou o Termo de Consentimento Livre e Esclarecido que foi confeccionado em duas vias uma para a pesquisadora e outra para o sujeito da pesquisa.

Ressalte-se que, a princípio, seria entrevistado um coordenador, dois assistentes sociais, dois psicólogos e um usuário de cada CRAS, segundo critérios do orientador da pesquisa, mas o município não possui coordenador de CRAS. Então se optou por entrevistar pelo menos um profissional de cada CRAS, desde que este se predispusesse, tendo em vista que quantitativamente o universo de pesquisa não é tão grande. Entretanto parte-se do pressuposto da amostragem qualitativa proposto pela autora, já citado. As entrevistas com os usuários foram realizadas, mas em função das orientações das bancas dos seminários do mestrado ${ }^{9}$, bem como o tempo para finalização da dissertação elas não foram analisadas.

As entrevistas com os profissionais ocorreram da seguinte maneira: apresentou-se uma folha digitalizada com os eixos norteadores, sendo que esta foi utilizada somente para orientar os entrevistados, os quais não ficaram "presos" ao papel.

Os sujeitos entrevistados narravam sobre suas vivências, sem preocupação de seguir um roteiro, embora tenham abordado todos os eixos; alguns seguiram uma linearidade outros não. Durante

\footnotetext{
${ }^{9} \mathrm{Faz}$ parte da grade curricular de metodologia do mestrado em Desenvolvimento Humano da Universidade de Taubaté a realização de seminários em que os alunos apresentam a pesquisa e são avaliados por uma banca composta pelos professores do curso.
} 
as entrevistas ficou acordado entre pesquisadora e pesquisado que a qualquer momento se necessário poder-se-ia realizar perguntas por ambas as partes.

Fitas as entrevistas, estas foram transcritas e editadas para o desenvolvimento das análises.

Destaca-se que de dezembro de 2011 a dezembro de 2012 a realidade do município mudou. Atualmente, o quadro de funcionários que compõe os CRAS aumentou: tem- se praticamente de dois a três assistentes sociais e dois psicólogos por CRAS, todos convocados em meados de dezembro de 2011 a janeiro de 2012.

\section{Resultados e discussões}

Diante do arcabouço teórico já pontuado, pode-se dizer que muitos são os que escrevem e pesquisam sobre a interdisciplinaridade. Mas, o conceito não está relativamente estável, pois suas definições são muitas e usadas de diferentes maneiras e em diversos contextos (POMBO, s.d., p. 2). No entanto, para compreendê-la no cerne desta discussão toma-se a definição apresentada por Ortiz (2011, p. 195) e Fazenda (2003, p. 39) respectivamente

Uma atuação interdisciplinar é, portanto aquela que possibilita a interlocução horizontal entre os diversos saberes e práticas, sem desconsiderar as particularidades de cada profissão, nem a natureza da contribuição de cada um dos sujeitos [...] trabathar em uma equipe interdisciplinar em minha opinião, significa, antes de tudo, compreender exatamente, em que consiste o objeto de intervenção de cada profissional integrante desse tipo de equipe.

Não se trata de ter nos homens o objeto da investigação, do qual o investigador seria o sujeito [...] mas, o seu pensamento-linguagem referido à realidade, os níveis de percepção dessa realidade, sua visão do mundo. Neste sentido, a interdisciplinaridade se preocuparia não com a verdade de cada disciplina, mas sim com a verdade do homem enquanto ser do mundo. Se assim não for teremos uma multidisciplinaridade.

Embora os profissionais não consigam conceituar formalmente o que é interdisciplinaridade, suas falas não fogem do exposto pelos autores. A maioria diz que desenvolve um trabalho interdisciplinar e procura realizar uma diferença com o multidisciplinar.
Na prática acho que isso oscila aqui, tem muitos momentos que a gente é multidisciplinar porque são vários profissionais no mesmo espaço trabalhando junto, mas cada um com a sua especialidade que até dialogam e se comunicam trocam figurinhas, mas na hora de agir cada um age da sua forma. Acho que algo que tem oscilado, pois de um tempo para cá a gente tem trabalhado mais como uma equipe interdisciplinar. $\mathrm{O}$ que eu entendo disso não sei se é o conceito exato, mas é quando a equipe tem uma questão, atende uma família, um indivíduo coisa e tal e consegue trabalhar junto, pode até atender separadamente ou junto, mas fala a mesma linguagem, está trocando figurinha sempre atende junto, a escuta nossa não é igual e não vai ser, a escuta do psicólogo é diferente do assistente social e isto é fato, por isso é interdisciplinar, porque eu acho que complementa. (Sujeito 1)

[...] a gente consegue fazer com que os conhecimentos sejam realmente unidos e não separados em saberes. Então nesse sentido é tranquilo não tem essa coisa de isso é meu e isso é seu, isso é do seu saber, há uma troca de saberes e que de acordo com a problemática, com o que vai ser trabalhado cada um pode disponibilizar o seu saber em função do objetivo. [...] porque multidisciplinar está completamente fora dessa questão socioeducativa, eu acho que não dá para juntar as duas coisas quando a gente faz multi é como a gente dividisse o próprio usuário, o próprio pensamento em compartimentos e ele não é compartimentado. (Sujeito 2)

Bom, agora você me pegou, pois a diferença entre eles eu já não ... acho que é interdisciplinar pois um complementa o outro, porque muitos profissionais acham que o assistente social tem que fazer a sua parte e o psicólogo ficar na sua sala fazendo o que é de sua parte. (Sujeito 3)

Acho que o trabalho interdisciplinar é muito rico, no CRAS onde eu trabalho isso acontece naturalmente no dia a dia. Em todas as questões seja nas atividades grupais ou individual a gente discute, os vários profissionais que já passaram por aqui na área da psicologia e do serviço social a gente sempre conversa discute, percebe as coisas de forma diferente [...] não existe uma maneira única de trabalhar, o trabalho não é dividido como coisa de assistente social e coisa de psicólogo.(Sujeito 4)

As pessoas precisam ser equipe, não que seja uma coisa massificada todo mundo igual, não! 
as pessoas são diferentes, mas elas precisão ter comprometimento, o comprometimento da classe trabalhadora, porque se ela sente trabalhadora eu acho que as coisas [...] a visão de mundo, a gente vai caminhar junto e com o mesmo objetivo, o objetivo da emancipação social, da inclusão e de tudo de bom que as pessoas tem. (Sujeito 5)

Assim, as apreciações mais citadas foram: "falar a mesma linguagem"; "troca de figurinhas"; "um complementa o outro"; "conhecimentos unidos e não saberes separados"; "unir forças, não haver competição profissional e não haver divisão, coisa de psicólogo e coisa de assistente social".

Embora os profissionais entendam que cada profissão tem suas especificidades, um dos sujeitos percebe que precisa ter uma postura e metodologia em comum.

Então, dentro de cada disciplina, de cada saber obviamente que dependendo de onde o problema se focaliza mais na área da assistência social ou na questão psicológico cada técnico vai trabalhar dentro do seu saber, mas de uma forma geral tanto o assistente social como o psicólogo tem a mesma forma de ver o problema, a mesma forma de encarar como aquilo... de acolher quem esta vindo é uma coisa bastante importante, pois ai não tem uma disputa de saberes, um não sabe mais que o outro. A gente vê que não são os profissionais que estão ali para atender é uma equipe [...] Então nesse sentido é tranqüilo não tem essa coisa de isso é meu e isso é seu, isso é do seu saber, há uma troca de saberes e que de acordo com a problemática, com o que vai ser trabalhado cada um pode disponibilizar o seu saber em função do objetivo (Sujeito 2)

Nota-se, que "a interdisciplinaridade decorre mais do encontro entre indivíduos do que entre disciplinas" (FAZENDA, 2003, p.71).

A autora também afirma que "a interdisciplinaridade leva todo especialista a reconhecer o limites de seu saber para acolher as contribuições das outras disciplinas" (p. 43). Isso é perceptível nas falas já citadas dos sujeitos, porém mais especificamente na fala a seguir:

[...] respeitar o saber do outro e de entender que eu não tenho a verdade, que tem coisa que eu não sei e tenho que perguntar para o outro, a gente trabalha isto com o grupo, mas às vezes a gente também está em débito com isto. Às vezes a gente é muito bom palestrante, orientador de grupos, mas às vezes o nosso trabalho interno quando vai discutir esses casos e vai conversar essas situações, a gente pega em resistências nossas; de aceitar isso, de pedir desculpas, pedir uma ajuda, a gente as vezes fala coisa que é do trabalho do outro dá uma opinião mais agressiva. [...] Então eu acho que quando os profissionais têm maturidade para aceitar critica, para ouvir, compartilhar, para falar do que faz e não ficar guardando para si eu acho que funciona bem e aqui eu avalio uma experiência muito positiva, um CRAS que eu não tenho a mínima vontade de trocar, porque eu vejo que aqui a gente tem diálogo. (Sujeito 1)

Outro elemento muito importante compreendido pelos sujeitos da pesquisa foi a concepção de a interdisciplinaridade permitir vislumbrar o usuário como um todo, inserido num contexto social que vai muito além da suas condições de vida e de suas escolhas pessoais, pois o trabalho interdisciplinar teve ser orientado por uma perspectiva de totalidade, que supere as expressões da questão social tidas atualmente como situações naturais do cotidiano (ORTIZ, 2011).

Coisa que eu não percebo a assistente social percebeu coisas que ela não percebe eu vou perceber, depois a gente consegue sentar junto um com o outro e junto com a família e dialogar junto eu acho que funciona muito mais porque a gente consegue ver a pessoa como um todo de fato, como diz a teoria, e a teoria só faz sentido se for vivenciada na prática.(Sujeito 1, grifo nosso)

Ele tem uma vida que envolve os conflitos familiares, as relações que ele tem, envolve a comunidade e isso tudo é um ser só e quando a gente faz esse trabalho interdisciplinar a gente consegue trabalhar com ele de uma forma única, a gente o vê como um todo; então não dá para dividir o usuário, a gente vem diz nesse momento seu aspecto é o emocional então é o psicólogo que vai dar conta, se o aspecto é material ou está passando por uma carência por falta de coisa então é com a assistente social, então a gente procura sempre trabalhar em todos os atendimentos de forma unida, juntos para que ele possa ser visto como ser único que isso é importante para ele e isso também é importante nos trabalhos em grupo.(Sujeito 2, grifo nosso)

[...] então a gente acaba tendo uma visão mais global daquela família e daquela pessoa então seria interdisciplinar e é muito rico. (Sujeito 3) 
Percebe-se que os três sujeitos, embora apresentem formações diferentes, notam que é na interação dos seus saberes, respeitando suas particularidades, que o objetivo maior é alcançado, ou seja, a melhoria da qualidade de vida dos usuários, a conquista ao direito reivindicado, a reflexão crítica da realidade, enfim a busca por uma transformação social que parta das ações coletivas. afirma:

Nessa perspectiva, Fazenda (2003, p. 36)

[...] uma reflexão verdadeiramente crítica nos possibilitará a compreensão em termos dialéticos das diferentes formas como o homem conhece. Então, a necessidade da superação da compreensão ingênua do conhecimento humano. O pensar crítico leva o homem a se descobrir em situação, a admirar a realidade e assim, apropriar-se da temática do conhecimento que não é fixa por não serem fixas as relações homem-mundo.

Entende-se que a interdisciplinaridade deve ocorrer não somente entre os profissionais, mas também entre os profissionais e o indivíduo/ o grupo/ a família, isto é, entre educador e educando. Acredita-se que é por meio desse trabalho que o sujeito torna-se protagonista da sua história possibilitando transformação. Fazenda (2003, p. 37), referindo-se à relação educador/educando diz: "[...] o aluno assume o papel de sujeito do conhecimento, através do diálogo com o educador." No caso da assistência social, os usuários podem assumir e devem assumir o papel de sujeitos.

Logo, assistentes sociais e psicólogos devem compartilhar de conceitos fundamentais como: direitos, autonomia, emancipação e cidadania para executar um trabalho interdisciplinar.

Para tanto, referenciados nos autores já citados apresentaremos alguns itens fundamentais para desenvolver um trabalho socioeducativo interdisciplinar:

- ter uma intervenção e uma prática interdisciplinar que deixe de lado o ordenamento social do capital, que minimiza os espaços de direitos e amplia as ordenações de disciplina dos corpos;

- pensar o exercício interdisciplinar que ultrapasse o mundo de especializações ${ }^{10}$;

\footnotetext{
${ }^{10}$ Ressalta-se que se entende o mundo das especificidades, porém propõe-se a partir da troca entre elas construir novos saberes e práticas.
}

- usar de uma metodologia que envolva a construção de um novo conhecimento a partir da teoria e da prática do assistente social e do psicólogo.

Não se deseja aqui desconsiderar os conhecimentos e as práticas já produzidos nas áreas da psicologia e do serviço social, mas "procurar desenvolver ações interdisciplinares que reflitam as experiências do trabalho", pois "[...] rompidas as fronteiras das disciplinas [...] impõe-se considerar que a interdisciplinaridade é condição também da prática social" (CAVALANTE; MORTARA, 2004, p.94).

Sendo assim, Fraga (2011, p. 187) conclui:

[...] o imperativo é o exercício do diálogo teórico-prático, a ultrapassagem e a destruição das fronteiras e dos muros. Esse exercício por vezes nos abre portas, outras vezes nos az fechá-las, mas, sobretudo, nos faz circular. No campo social, não é o domínio de determinado conhecimento, não é a delimitação de uma área ou de determinada técnica ou método que traz a especificidade do campo, o que faz a especificidade do campo são as verdade que ele nos coloca, não estamos falando de campos diferentes, estamos falando de fenômenos humanos.

A narrativa de um sos sujeitos é importante, embora sua fala não se assemelhe em alguns aspectos com as demais. Ele insere no debate, mesmo sem intenção de fazê-lo ou dizê-lo, um elemento fundamental: a intersetorialidade.

Como você sabe o trabalho aqui no CRAS muitas vezes é prejudicado por falta de recursos, e um deles seria utilizar a multidisciplinaridade para favorecer nosso trabalho. Vejo hoje o trabalho do CRAS apenas interdisciplinar, apesar de estarmos sempre procurando contato com profissionais de outras áreas. Penso que para o fortalecimento do combate à pobreza e acesso aos direitos, o trabalho socioeducativo é um instrumento eficaz, que deveria ser sempre multidisciplinar, a fim de proporcionar ao grupo maior clareza sobre diversos eixos de estudos e de temas das problemáticas que apresentamos e os indivíduos nos trazem. Enquanto isso não acontece com frequência, buscamos aperfeiçoamento. (Sujeito 6)

A multidisciplinaridade colocada pela assistente social diz respeito à participação de outros profissionais das demais políticas: saúde, educação, 
cultura, habitação etc., não se restringindo somente aos assistentes sociais e psicólogos dos CRAS. Porém tal elemento constitui a intersetorialidade (integração de vários setores). A assistente social consegue sem perceber, falar da importância de as políticas trabalharem juntas para serem eficazes nas propostas e na execução das intervenções para o exercício da cidadania dos indivíduos, famílias e/ou grupos por eles atendidos.

A intersetorialidade pode ser vista como uma alternativa estratégica. Para Magalhães (2004 apud ASSIS, 2012, p. 2), por meio da prática intersetorial é possível superar a realização de ações fragmentadas, sobrepostas e dispersas. No entanto, não basta estabelecer um diálogo entre os diferentes atores envolvidos em políticas complementares para a concretização dessa prática. "É preciso que as políticas tenham um objetivo e um foco comuns, construídos dialogicamente desde o momento de compreensão do problema a ser superado por elas" (ASSIS, 2012, p.2).

O autor enfatiza também que a prática intersetorial implica ver o cidadão de forma integrada; assumir o impacto integralizado, coletivizar toda a etapa da política pública. E isso se dá tanto no planejamento como durante todo o processo se houver compreensão entre a minha ação específica do profissional e a transversalidade dos problemas, definindo de forma compartilhada o objetivo em comum (ASSIS, 2012)

Assim,

[...] entende a intersetorialidade como um conceito com diferentes acepções que variam de acordo com as premissas que cada uma delas assume, inclusive a respeito da própria ideia de setor. Para ela, dois pressupostos devem ser assumidos quando da adoção desse conceito. Primeiramente, a busca por soluções integrais, que podem levar ao alcance de objetivos de desenvolvimento mais arrojados. Essa premissa diz respeito a um fundamento político que considera que as políticas públicas devem ser elaboradas e implementadas de maneira intersetorial, sendo que a ideia de setor se relaciona às diferentes áreas institucionais de ação do governo (assistência social, saúde, educação, habitação etc.). Em segundo lugar, pressupõe-se que a articulação entre os setores promove o aproveitamento da especialidade de cada um deles no enfrentamento dos desafios sociais. Nesse caso, assume-se um fundamento técnico: a intersetorialidade possibilita que se partilhe os recursos de cada área da ação governamental e, assim, pode-se desenvolver ações políticas mais efetivas. Esse pressuposto considera, enfim, a ideia de setor de maneira ampliada, como a articulação entre governo, sociedade e mercado (GRAU, 2005 apud ASSIS, 2012, p. 3-4)

Tal pensamento não estaria de todo desconexo do que já foi abordado se analisado a partir do que Fazenda (2003, p. 69) comenta quando discorre sobre parcerias e interdisciplinaridade ${ }^{11}$.

A parceria, portanto, pode constituir-se em fundamento de uma proposta interdisciplinar, se considerarmos que nenhuma forma de conhecimento é em si mesma racional. A parceria numa tentativa de iniciar o diálogo com outras formas de conhecimento a que não estamos habituados e, nessa tentativa, a possibilidade de interpenetração delas.

Todavia, dentro da realidade vivenciada pelos sujeitos da pesquisa a interdisciplinaridade é tida como essencial para atuações/intervenções, principalmente no que se refere à consolidação da cidadania, já que estes profissionais trabalham na política de assistência social, que tem como objetivo maior garantir o acesso aos direitos.

\section{Considerações finais}

Nenhuma pesquisa começa por acaso e/ou do nada, pois estamos inseridos em um contínuo processo que nos leva a questionar toda dinâmica da realidade vivenciada.

Assim, ao pensar nas transformações da política de assistência social em sua trajetória histórica, enfatizando a relação profissional-usuário nota-se como a ação interventiva do trabalhador social torna-se fundamental na execução e na consolidação daquilo que é proposto não só pela política, mas também pelo projeto societário e ético-político das profissões.

Então, ao partir da premissa de que atualmente a interdisciplinaridade é referência para a prática interventiva dos profissionais, este artigo teve como objetivo maior compreender a percepção dos trabalhadores sociais (assistentes sociais e psicólogos)

\footnotetext{
${ }^{11}$ Para maiores detalhes sobre o assunto consultar FAZENDA (2002).
} 
acerca do trabalho interdisciplinar realizado com as famílias nos Centros de Referência de Assistência Social (CRAS).

Identificamos que muitos são os limites, porém diversas são as possibilidades inscritas neste trabalho desenvolvido pelos trabalhadores sociais nos CRAS.

O trabalho nos CRAS é percebido pelos profissionais como interdisciplinar, pois eles acreditam que o mesmo concebe o indivíduo e/ou a família como um todo sem separação de saberes, favorecendo o rompimento do pensar fragmentado e individualizado nas relações sociais, imposto pelo contexto contemporâneo do desenvolvimento das forças produtivas o qual prioriza a supremacia do indivíduo e dos interesses privados sobre o coletivo.

Embora se constate que os profissionais não saibam conceituar formalmente a interdisciplinaridade, todos os profissionais afirmam desenvolver um trabalho interdisciplinar, o qual assume uma dimensão muito importante no seu cotidiano, pois proporciona uma intervenção que vislumbra o todo e ultrapassa o mundo das especializações e da fragmentação;

Assim, a interdisciplinaridade emerge como questão necessária na prática dos profissionais dos CRAS, já que estes estão diretamente ligados ao enfrentamento das expressões da questão social.

Portanto, reconhecer o trabalho interdisciplinar e tudo que ele acarreta como peça essencial na concretude dos serviços, programas e projetos do CRAS significa também reconhecer os avanços na luta social pelo efetivo e concreto acesso aos direitos previstos na Lei orgânica de Assistência Social (LOAS) e na PNAS, tendo como protagonista dessa conquista a transformação dos usuários da assistência social e das demais políticas públicas.

Desse modo, conclui-se que dentro da realidade vivenciada pelos sujeitos da pesquisa a interdisciplinaridade é tida como essencial para suas atuações/intervenções, principalmente no intuito de construir uma práxis mais reflexiva e coletiva que leve à consolidação da política de assistência social como direito.

\section{Referências bibliográficas}

ALVES, F. M. S.; REINERT, J. N. Percepções dos coordenadores dos cursos de graduação da UFSC sobre a multidisciplinaridade dos cursos que coordenam. Avaliação (Campinas), Sorocaba, v.12, n. 4, dez 2007. Disponível em: http//www.scielo.br/scielo. Acesso 27 nov. 2012.

ASSIS, M. A. Reflexões sobre a prática intersetorial: que caminhos? Plano de Capacitação para implementação da NOB-RH. Disponível em: http://learning.fundap.sp.gov.br/ portal/course/view.php?id=142. Acesso em: 16 out. 2012.

BERHING, E. R.; BOSCHETTI, I., Política social: fundamentos e histórias. 8 ed. São Paulo: Cortez, 2011.

BICALHO, L. M.; OLIVEIRA, M. Aspectos conceituais da multidisciplinaridade e da interdisciplinaridade e a pesquisa em ciência da informação. Revista Eletrônica de Biblioteconomia e Ciência da Informação, v.16, n. 32, p. 1-26, abril de 2011. Disponível em: www.períodicos.ufsc. br/index.php/br/article/viem/1518_2924. Acesso em: 27 de nov. 2012.

BRASIL. Ministério do Desenvolvimento Social e Combate à Fome. Caderno de Orientações Técnicas sobre o PAIF. Brasília: Ministério do Desenvolvimento Social e Combate à Fome, 2012.

BRASIL. Resolução n ${ }^{\circ}$ 109, de 11 de novembro de 2009. Tipificação Nacional de Serviços Socioassistenciais. Brasília: Oficial da República Federativa do Brasil, 25 nov. 2009.

BRASIL.. Política Nacional de Assistência Social. Brasília: Ministério do Desenvolvimento Social e Combate à Fome. Secretaria Nacional de Assistência Social DF, 2004.

CAVACANTE, O; MORTARA, P. C. Interdisciplinaridade no trabalho socioeducativo. In: WANDERLEY, Mariângela Belfiore (Org.). Trabalho com famílias: textos de apoio. São Paulo: Ed. IEE-PUC, 2004. v.2.

CONSELHO FEDERAL DE SERVIÇO SOCIAL. Parâmetros para atuação de assistentes sociais e psicólogos (as) na política de assistência social. Cartilha final, 2007. Disponível em <htpp//www.cfess.org.br/ arquivos/cartilhafinal $>$. Acesso em 13 jun. 2011

COSTA, L. C., Questões sociais e políticas públicas tendências atuais do debate. Revista Políticas Públicas. Pelotas: Universidade Católica de Pelotas, 2007.

EIDELWEIN, K., Psicologia e serviço social: uma relação interdisciplinar na direção da produção de conhecimento. Textos e Contextos, v.6, n. 2, p. 298-313, Porto Alegre, 2007.

FAZENDA, I. C. A. Interdisciplinaridade: qual o sentido? São Paulo: Paulus, 2003. 
Interdisciplinaridade, um projeto em parceria, 7. Ed. São Paulo: Loyola, 2002.

FURLANETTO, E. C. Interdisciplinaridade: um conhecimento construído nas fronteiras. International Studies on Law and Education - CMOROC- Feusp/ Universidade do Porto, agosto de 2011.

FRAGA, V. Interdisciplinaridade e assistência social. In: Conselho federal de Serviço Social. O trabalho do/a assistente social no SUAS: Seminário Nacional. Brasília: CFESS, 2011, p. 180-187.

GADOTTI, M. Marx: transformando o mundo. São Paulo: FTD, 1989.

IAMAMOTO, M. V. O serviço social na cena contemporânea. In: Conselho Federal de Serviço Social; Associação Brasileira de Ensino e Pesquisa em Serviço Social. Serviço social: direitos sociais e competências profissionais. Brasília-DF: CFESS/ABEPSS, 2009.

.A questão social no capitalismo. Temporalis. 2 ed., n.3, Brasília, jan./jul. 2004.

IBGE. Censo 2007. Disponível em <HTTP: www.ibge.gov. br/home >. Acesso em 6 jun. 2011.

LENOIR.Y. Três interpretações da perspectiva interdisciplinar em educação em função de três tradições culturais distintas. Revistas E-Curriculum, PUCSP, v.1, n.1, São Paulo, 2005. Disponível em: http://www.pucsp.br/ ecurriculum. Acesso em 28 de nov. de 2012.

MANDEL,E.,Acrisedocapital: os fatos esuasinterpretações marxistas. São Paulo: Ensaio; Campinas:UNICAMP, 1990.

MINAYO, M. C. S., Disciplinaridade, Interdisciplinaridade e complexidade. Revista Emancipação. v. 10, n. 2, p. 435442, Ponta Grossa/PR, 2010.

Pesquisa social: teoria, método e criatividade. 18. ed. Petrópolis: Vozes, 1994. (Coleção Temas Sociais)

MOTA, A. E., Crise contemporânea e as transformações na produção capitalista. In: Conselho Federal de Serviço Social; Associação Brasileira de Ensino e Pesquisa em Serviço Social. Serviço Social: direitos sociais e competências profissionais. Brasília: CFESS/ABEPSS, 2009.

ORTIZ, F. S. Interdisciplinaridade e assistência social. In: Conselho Federal de Serviço Social. O trabalho do/a assistente social no SUAS: Seminário Nacional. Brasília: CFESS, 2011, p. 188-199.

PIRES, M. C. Multidisciplinaridade, interdisciplinaridade e transdisciplinaridade no ensino. Interface, v.2, n.2, Botucatu, fev. 1998. Disponível em: http//www.scielo. php?script $=$ sci_arttext\&pid $=$ S14143283199800010\&ing $=P$ T\&nrm=iso. Acesso em: 27 de nov. 2012.
POMBO, O. Epistemologia da interdisciplinaridade. Disponível em: www.educ.fc.pt/docentes/opombo/ investigação/portofinal.pdf. Acesso em: 08 de jul. 2012

PONTES, R. A categoria de mediação em face do processo de intervenção do serviço social. Boletin Electrónico Surá, Costa Rica: Universidad de Costa Rica, 1999. Disponível em: WWW.ts.ucr.ac.cr/suradoc.htm. Acessado em 07 mar. 2012.

YAZBEK, M. C. Estado e políticas sociais. Política social e serviço social: elementos históricos e debate atual. Revista Praia Vermelha. v.18, n.1, Rio de janeiro: UFRJ, 2008.

Artigo Submetido: 22/02/2013

Artigo Aprovado:13/09/2013 